\title{
Epigenetic Regulation as a Basis for Long-Term Changes in the Nervous System: In Search of Specificity Mechanisms
}

\author{
A. A. Borodinova ${ }^{1, a *}$ and P. M. Balaban ${ }^{1}$ \\ ${ }^{1}$ Institute of Higher Nervous Activity and Neurophysiology, Russian Academy of Sciences, 117485 Moscow, Russia \\ ${ }^{a}$ e-mail: borodinova.msu@mail.ru
}

Received June 1, 2020

Revised July 16, 2020

Accepted July 29, 2020

\begin{abstract}
Adaptive long-term changes in the functioning of nervous system (plasticity, memory) are not written in the genome, but are directly associated with the changes in expression of many genes comprising epigenetic regulation. Summarizing the known data regarding the role of epigenetics in regulation of plasticity and memory, we would like to highlight several key aspects. (i) Different chromatin remodeling complexes and DNA methyltransferases can be organized into high-order multiprotein repressor complexes that are cooperatively acting as the "molecular brake pads", selectively restricting transcriptional activity of specific genes at rest. (ii) Relevant physiological stimuli induce a cascade of biochemical events in the activated neurons resulting in translocation of different signaling molecules (protein kinases, NO-containing complexes) to the nucleus. (iii) Stimulus-specific nitrosylation and phosphorylation of different epigenetic factors is linked to a decrease in their enzymatic activity or changes in intracellular localization that results in temporary destabilization of the repressor complexes. (iv) Removing "molecular brakes" opens a "critical time window" for global and local epigenetic changes, triggering specific transcriptional programs and modulation of synaptic connections efficiency. It can be assumed that the reversible post-translational histone modifications serve as the basis of plastic changes in the neural network. On the other hand, DNA methylation and methylation-dependent 3D chromatin organization can serve a stable molecular basis for long-term maintenance of plastic changes and memory.
\end{abstract}

DOI: $10.1134 / \mathrm{S} 0006297920090023$

Keywords: memory, learning, epigenetics, gene expression, histone deacetylase, DNA methylation, nitric oxide

\section{INTRODUCTION}

There is a vast number of studies regarding mechanisms of memory, however, up to now there is no consensus on molecular mechanisms of the formation and longterm retention of the memory trace, as well as on effective approaches for changing the memory and correction of its pathologies. During the last years many data has been accumulated indicating that long-term changes in the nervous system, including memory, are associated with changes in the expression of certain gene groups [1, 2]. Understanding of how the specific control of the separate gene groups is realized at certain times in certain functional neural networks during learning and what mechanisms are behind the maintenance of these changes is very

Abbreviations: DNMT, DNA methyltransferase; $\mathrm{H} 3 \mathrm{~K}(\mathrm{n}), \mathrm{n}^{\text {th }}$ lysine of the third histone; HAT, histone acetyltransferase; HDAC, histone deacetylase; NO, nitric oxide; PK, protein kinase; PP, protein phosphatase.

* To whom correspondence should be addressed. important. Since the long-term memory is acquired by any animal and is not reflected in the genome structure, but is a result of changes in the expression levels of certain genes, by definition it is considered as an epigenetically regulated phenomenon $[2,3]$. It was shown experimentally in vitro and in vivo that plasticity and memory mechanisms are closely associated with epigenetic rearrangements, which control accessibility of the definite sites of the genes for different regulatory molecules [4-6]. In the framework of this review, some components of the specific control of the gene expression on the molecular and cellular levels are discussed together with the role of epigenetics in these processes.

\section{BEHAVIOR AND EPIGENETICS: WHETHER THERE IS A SPECIFICITY?}

When dependence of behavioral changes (including the long-term changes - memory) on various molecular processes are analyzed, it is extremely important to under- 
stand the specificity level of relationships of the phenomena under study. There is no doubt that changes in virtually all molecular or neurochemical processes should affect activity of neurons and behavior, therefore, the standard approach involving selective blockade of some molecular system and analysis of changes in the behavior can show only that this system is active in the brain.

The necessity of synthesis a new protein (translation) and of RNA synthesis for long-term changes in the behavior (memory formation) was shown rather long ago in the gastropod Aplysia [7]. It was also shown for the first time for the same mollusk that the known stimulator of plastic processes, serotonin, induced assembly of activator complexes of the transcriptional factor CREB1 with histone acetyltransferase CBP and caused acetylation of histones in the promoter of the plasticity-related gene $\mathrm{C} / \mathrm{EBP}$, which correlated with the level of its expression [8]. On the other hand, FMRFa, the inhibitory neuropeptide mediator that is competing with serotonin, facilitated binding of the CREB2 transcription factor to the gene promoter and stimulated histone deacetylation via recruiting HDAC5 histone deacetylases. Electrophysiological experiments on the identified sensory neurons revealed that serotonin increased synaptic responses, whereas FMRFa led to depression of these responses. Taking into account the known role of these neurons in the behavior, this work can be considered as one of the first studies, which showed the role of posttranslational histone modifications in the regulation of synaptic plasticity affecting animal's behavior [8].

Vast amount of literature data has been accumulated during recent years regarding the balance of histone acetyltransferases (HATs) and histone deacetylases (HDACs). Changes in this balance disrupt/improve plasticity, memory, and learning processes in adult animals [5]. Disorders in this balance not only change efficiency of learning, but correlate with many neuropathologies. Using inhibitors changing the epigenetic balance could be a basis for treatment of these pathologies [9]. Inhibition of HDACs is widely used in order to change cognitive abilities of animals, including the long-term memory [5, 9]. HDAC inhibitors were shown to have positive effect on formation and recovery of the synaptic plasticity and memory not only in mammals, but also in drosophila [10] and chicken [11]. The possibility to improve contextual memory and rescue the impaired memory by injection of HDAC inhibitor, sodium butyrate, was demonstrated for mollusks. The important fact established in this study was that the HDAC inhibitor did not change magnitude of the behavioral response under normal conditions, but acted selectively on the response magnitude of the same animal only under conditions of learning, i.e., enhanced the memory, not changing behavior under normal conditions [12].

A comparative study on the role of histone deacetylases HDAC1 and HDAC2 in mice revealed that the increase in expression of HDAC2, but not of HDAC1, led to decrease in the synapse density, impaired synaptic plasticity and memory formation, but these phenomena could be reversed by using HDAC inhibitors [13]. It should be noted that majority of the HDAC inhibitors are not specific, therefore, the results are ambiguous considering different roles of HDAC1 and HDAC2. From this standpoint the study by Morris et al. is interesting. They used knockout mice, and the roles of HDAC1 and HDAC2 were evaluated separately [14]. It was shown that in the HDAC2-knockout mice the extinction rate of conditioned fear responses and a conditioned taste aversion were accelerated, while the attention tasks were performed better by these animals than by the control mice. Impairment of the motor training and episodic memory was not observed in these mice that directly indicated specificity of the HDAC2 involvement in different behavioral tasks. The authors concluded that inhibition of the HDAC2 activity improved the associative learning without affecting the nonassociative processes [14].

It is important that changes in the chromatin compaction are for the most part reversible and only "remove the brakes", opening possibility for the long-term changes in the gene expression [2]. On the other hand, the long-term retention of information in the nerve cells can be associated with other epigenetic processes occurring on the level of DNA. The pioneer works during the 1970-1980s presented interesting data on the coupling of the plastic processes in the nervous system and DNA methylation. In their work Vanyushin et al. examined changes in the DNA methylation in the functionally active regions of the rat brain that were considered by authors as the mechanism of triggering gene transcription during learning [15, 16]. Already in 1976 separation of nuclei from the neurons and glial cells by ultracentrifugation allowed to conclude that during development of the conditioned reflex the physiological processes affected first the genome of more labile and fast responding cells neurons, and were likely associated with the involvement of some specific sites of DNA [16]. Later Holliday [17] suggested that methylation of DNA could be a mechanism of the long-term memory maintenance in a neuron. It was assumed that in the neurons of networks (engrams), involved in the specific memory, the methylation state of some DNA sites could change in response to specific stimuli, and that this state would be preserved for a long time, because some data showed that in the case of DNA damage the cytosines methylated previously were methylated again, thus maintaining the general pattern of DNA methylation [18]. Taking into account the number of methylation sites and the number of neurons, the informational capacity of such memory maintenance is very high. Holliday also considered modifications of histones as a possible epigenetic mechanism, but thought that because of the absence of covalent bonds of histones with DNA, stability of these changes would be markedly 
lower than the cytosine methylation in DNA. Later these predictions were confirmed experimentally by many works using mammals and invertebrates [3, 18-20]. Considering that DNA methylation is usually associated with the decrease in the gene activity, presence of hypermethylation after learning seems to indicate a continuous suppression of activities of certain groups of genes. This idea was corroborated by the studies on mammals and mollusks [19, 21].

In the work [3] a whole-genome analysis of chromatin was performed in detail, and gene expression profile was analyzed for the two brain regions, which were vital for the contextual defense memory (the CA1 zone of hippocampus and the anterior cingulate cortex), for different cell types (neurons, glia), and three time points before and after formation of the contextual memory in mice [3]. The authors found that the pattern of changes in the DNA methylation exhibited good correlation with the known data on the spatial localization of memory, stable and dynamic changes were found in the neurons. It is essential to note that histone methylation was observed in neurons and glial cells, and seemed to be global with a small number of local changes.

It is believed that post-translational changes in chromatin are mainly associated with the phase of the memory consolidation $[22,23]$ that is manifested also by the absence of correlation between the histone methylation and the differential gene expression during the memory maintenance [3]. In this work changes in the DNA methylation were observed during the consolidation phase and also lasted during the memory maintenance. The role of DNA methylation is also considered in the literature as a mechanism for stabilization of the neural circuit (engram) activity during consolidation, which is the basis for successful maintenance of the memory [24].

Thus, it can be assumed that reversible post-translational modifications of histones underlie plastic changes in the functional neural networks [2]. On the other hand, DNA methylation changes gene expression over a long period (lifetime), and since neurons of adult animals do not divide, it can serve a stable molecular basis for maintenance of plastic changes and memory.

\section{SPATIAL-TEMPORAL EPIGENETIC REARRANGEMENTS IN FUNCTIONAL NEURAL NETWORKS}

Formation and maintenance of the memory trace depends on the coordinated and fine-tuned work of different groups of epigenetic regulators in the certain brain areas and at different learning paradigms. Stimulusdependent changes in the epigenetic landscape in the specific functional neural networks or brain regions are in reality reflecting the character and duration of the regula- tion of transcriptional processes, in other words, a "critical window" for plastic changes.

Region-specific epigenetic rearrangements. Today the overwhelming amount of information concerning dynamics of epigenetic changes (post-translational modifications of histones, DNA methylation) during learning or memory retrieval has been obtained in the course of analysis of different regions of the brain (subcortical structures and the cortex regions) [3, 20, 22, 25-28]. Epigenetic changes in the regulatory regions of some plasticity-related genes are shown to correlate with the level of their expression [3, 20, 22, 25-28]. Heterogeneity of the specimens under analysis can make difficult interpretation of the data. According to the current concepts, the memory trace can be "encoded" in the specific functional networks (engrams) of certain regions of the brain during learning, therefore, studies on molecular mechanisms underlying engram-specific consolidation and reconsolidation (repeated consolidation at the reactivation) of the memory will be the logical and interesting continuation of this line of research.

The region-specific rearrangements of chromatin and DNA methylation were found to be correlated with the involvement of the corresponding brain structures or even definite engrams in the consolidation of recent and remote memory $[3,25]$. The initial memory consolidation in the hippocampal network (the recent memory; hours-days) [29] is accompanied by a rapid but reversible enrichment of some post-translational histone modifications (acetylation, methylation, phosphorylation) and of DNA hydroxymethylation [23, 25, 28]. Later, contribution of the hippocampal networks to the memory consolidation decreases gradually with increase of the role of the cortical networks [29]. Functional networks of the cortex regions associated with the maintenance and retrieval of the long-term memory (the remote memory; days-weeks) are established immediately during the learning, but contribution of these engrams to the memory consolidation grows with time along with their "maturation" (morphological and functional) $[23,29]$. Several investigations of the temporal characteristics of epigenetic rearrangements in the cortical regions provide contradictory data, which do not lead to the unambiguous conclusion. According to some data, epigenetic rearrangements of chromatin in the prefrontal cortex appear with a delay $(24 \mathrm{~h})$, but are maintained without changes for at least a week [25]. According to another work, epigenetic changes in the orbitofrontal cortex are reversible [23].

It was shown that during the learning process functional connections between the cells of the subcortical structures (hippocampus, amygdala) and cortical neurons were changed in a certain way that unite the affected neurons into an engram [29]. The inputs from the hippocampus, entorhinal cortex, and amygdala provide a certain level of the network activity, which influences the estab- 
lishment and "maturation" of the functional cortical networks [23, 29]. Targeted suppression of the activity of any of these inputs (chemical or optogenetical) during the learning leads to the subsequent impairment of the remote memory.

We hypothesize that the signals from the subcortical structures could trigger epigenetic changes in the cortical neurons that could contribute to the "memory maturation" in the cortical networks. In an interesting work, in which plastic changes in the medial prefrontal cortex of rats were induced in vivo using the high-frequency stimulation protocol, the delayed and long-term (hours) increase was observed in the activity of the key epigenetic regulators [histone acetyltransferases, DNA methyltransferase (HAT, DNMT)] leading to massive chromatin rearrangements [27], what seems to be in agreement with our hypothesis. Selective testing revealed epigenetic changes in the promoter regions of some "plasticity-related genes" (Bdnf, Reln) coupled with the increase in their transcription and translation. Products of these genes could participate in the changes of structural characteristics and efficiency of connections between the neurons $[30,31]$. In another work, a rapid but reversible increase in the acetylation of histones was observed in the orbitofrontal cortex of animals following learning [23]. In these animals the number of synaptic spines increased with time. Injections of inhibitors of histone deacetylases shortly after the learning not only prolonged the acetylated status of histones, but also stimulated spines formation and improved remote memory of the animals that was not observed in the case of the delayed injection of these substances [23]. Studies on molecular mechanisms underlying the increase in the histone acetylation in the orbitofrontal cortex in response to learning revealed association with activation of the MAPK/ERK1/MSK1 signaling cascade. Inhibition of the activities of these kinases was accompanied by disappearance of epigenetic and morphological rearrangements in the cortex and by disruption of the remote memory [23].

Synergetic epigenetic rearrangements in different regions of the brain. The strategy of targeted changes of histone acetylation or methylation and of DNA methylation in some regions of the brain is commonly used during investigation of the regulation of learning efficiency and memory $[4,6]$. Several works resulted in a rather interesting conclusion: a directed change of the epigenetic landscape in one structure of the brain could correlate with chromatin rearrangements and changes in the gene expression in the other structure affecting efficiency of the connections between the brain regions/engram elements [26, 32]. In particular, the change in epigenetic profile in the entorhinal cortex of the animals during learning (decrease of repression marks $\mathrm{H} 3 \mathrm{~K} 9 \mathrm{me} 2$, increase of active marks $\mathrm{H} 3 \mathrm{~K} 9 \mathrm{ac}, \mathrm{H} 3 \mathrm{~K} 4 \mathrm{me} 3$ ), caused by local injection of the inhibitor of histone methyltransferases G9a/GLP is accompanied by an unexpected enrichment of repressive histone marks $\mathrm{H} 3 \mathrm{~K} 9 \mathrm{me} 2$ in the CA1 area of the hippocampus [26]. Epigenetic manipulations in the entorhinal cortex, which is one of the important points for information exchange between the hippocampus/cortex and the amygdala/cortex, affect the promoter regions of some plasticity-related genes (DNMT3a, Egr1, Bdnf) and lead to improvement of the contextual (hippocampus-dependent) and key (amygdala-dependent) memory, possibly, due to the change in the effectiveness of the entorhinal cortex connections with other structures [26]. On the contrary, inhibition of the G9a/GLP in the hippocampus of animals during learning is accompanied by the growth of the number of active histone marks $\mathrm{H} 3 \mathrm{~K} 4 \mathrm{me} 3$ in the entorhinal cortex [26]. According to the literature, changes in the amygdala activity are also associated with modulation of the molecular cascades in the structures functionally connected with it. In particular, injection of the HDAC inhibitor into basolateral amygdala is accompanied by the increase in the amount of BDNF protein in the dorsal hippocampus of the animals during learning [32]. The presented data indicate that dynamic epigenetic rearrangements of chromatin in some structures of the brain can influence molecular characteristics in the other structures, possibly, due to the changes in the activity of these structures and the nature of their interaction.

Thus, the change of epigenetic landscape early after the learning seems to be vital for "readjustment" of the network to provide the long-term maintenance of the memory trace, and, moreover, artificially induced epigenetic rearrangements of chromatin facilitate more efficient functional "rearrangement" of the hippocampuscortical and cortex-cortical connections.

\section{SPECIFICITY OF EPIGENETIC REGULATION OF THE PLASTICITY-RELATED GENES}

Precise changes in the gene expression occurring in a timely fashion, including changes in the plasticity transcriptome, in response to changes in the synaptic activity of neurons are based on the complex interactions between epigenetic modifications of histones, involvement of regulatory proteins, and changes in the DNA methylation levels. The pattern of gene expression in the brain of adult animals depends on the neuronal activities and behavioral experience (which reflects neuronal activity). These changes are critical for adaptive changes of the behavior, including associative long-term memory [20, 33, 34]. Changes in the synaptic efficacy and the cell membrane excitability influence the character of connections between the neurons, regulate activity of the neural network, and trigger modulations of transcription of certain groups of activity-related genes. In the literature, the genes of the early and late response are discriminated [35, 36]. These sets of genes differ in the necessity of synthesis 
of new proteins and in the rate of induction of the expression changes. Recently, it was experimentally shown that different patterns of the cellular activity induce different gene expression programs. Depending on the stimulus duration, a gradual increase in the involvement of genes from the early (primary) and the late (secondary) response was observed [37]. Short-term stimulation of the cultured cortical neurons or of the visual cortex neurons in vivo is sufficient for activation of expression of a small group of the early response genes with very rapid kinetics (the immediate early genes). It is important to note that the first wave of transcription does not depend on the de novo protein synthesis. Some of these first wave genes are activated in response to a wide set of external stimuli and apparently present a necessary and universal, but unspecific part of the cellular response. The authors showed that the first wave of transcription was followed by the second and third transcription waves on prolongation of the stimulation, which affected the early response genes with the slow kinetics, and the late response genes, respectively [37]. The late response genes change their expression with a pronounced delay, require synthesis of new proteins for changes to occur, their expression is regulated by the protein products of the early response genes $[35,36]$.

Stability of the spontaneous activity of neurons was analyzed in a very interesting work on a culture of mouse cortical neurons [38]. A hypothesis was tested that the activity-dependent transcription necessary for supporting constant activity level (neuronal activity homeostasis); however, homeostasis was observed also in the neurons with the suppressed activity of the plasticity-related gene $A r c$ and in the absence of the activity-dependent transcription factors AP1 and SRF. The authors concluded that the activity-regulated transcription was not necessary for the constantly maintained activity of the neuron [38].

An interesting hypothesis concerning the relation between the synaptic and epigenetic mechanisms of the memory maintenance was suggested in the work by Kyrke-Smith and Williams [2]. Based on the idea that changes in the synaptic efficacy during the learning underlie the long-term changes in the functioning of the neural network (the memory engram), the authors suggested a mechanism for formation and maintenance of the memory engrams. Their hypothesis proposed to isolate the "plasticity transcriptome", which underlies structural and functional modifications of synaptic connections in the network during the learning and several hours after (time of the memory consolidation). This is the time of maximal activity of the genes, products of which are associated with plasticity (CREB, Egr1, AP1, Arc, BDNF), and this period ends with activation of their repressors (histone deacetylases) at the beginning of transition to the "memory maintenance transcriptome" [2]. In fact, the authors identify the role of histone acetylation specific for memory formation and maintenance as a sep- arate mechanism of metaplasticity, which regulates maintenance of the memory engram. For our analysis it is very important to characterize a "permissive epigenetic state", which coincides with the period of induction of longterm changes in the functioning of neural networks (consolidation, reconsolidation). This epigenetic "state" could be considered as an open window for long-term changes. The authors of the hypothesis apparently have in mind specificity of epigenetic regulation of the specific set of genes changing their expression during the plasticity induction, during formation of the long-term changes, but not during the memory maintenance. Clear formulation of the role of epigenetic regulation during the memory formation and maintenance - possibility of the changes is blocked epigenetically at rest, and removal of the epigenetic "brakes" temporary opens a possibility for changes in the gene expression, whereas during maintenance of the already formed memory the possibility of long-term changes is prevented again - is a significant contribution of this study.

Considering mechanisms of the memory maintenance and regulation in the neural network, we inevitably come to the opposing processes occurring in the individual synapse and in the nucleus of a neuron. In the latter case, the changes affect all synapses of the neuron. The epigenetic regulatory mechanisms of the memory formation and maintenance are more likely to be the latter, since the changes in the expression of any gene in the case of synthesis of a protein product of the gene within the cell should equally affect all the synapses of the given cell. Unique exceptions to this rule are also known, when mRNA goes to the synapse directly and translation occurs just in the synapse. This was established for the two most important genes, products of which were shown to participate in the memory formation (Arc) and maintenance (PKM $\zeta)$ in multiple studies [39, 40].

It seems that the basic principles of the memory formation and maintenance should be rather conservative, because the same regulatory molecules are present in snails, flies, and in humans. Due to the highly conserved histone proteins in the line of organisms from the simplest invertebrates to humans, epigenetic modifications of chromatin can occur via similar processes in the distant groups of organisms; therefore, they could be considered as the unique and efficient way for the long-term regulation of nerve cell functioning and the basis for memory encoding.

\section{HYPOTHESIS OF THE "MOLECULAR BRAKES" AND APPROACHES FOR STIMULUS-SPECIFIC REGULATION OF GENE ACTIVITIES}

Almost 10 years ago, a hypothesis was proposed, according to which the HDAC complexes with various co-repressors could be considered as "molecular brake 
pads" of the specific gene expression (see below) [41]. A temporary removal of these "molecular brake pads" for activation of gene expression can occur only in response to the sufficiently strong physiological stimuli [41]. This review does not aim to describe all possible biochemical mechanisms required for the temporary removal of "molecular brake pads" in the functional networks of neurons under physiological loads, but further we will focus on those mechanisms which we think are the most relevant and specific.

Structure of repressor complexes. Chromatin-associated repressor complexes are high-order multiprotein clusters with the central part apparently presented by the class I histone deacetylases (HDAC I) [42]. Interactions between HDAC I and other histone deacetylases (class HDAC II), some histone methyltransferases (SUV39H1), histone demethylases (JMJD2A and LSD1), DNA methyltransferases (DNMT3a, DNMT3b, DNMT1), and protein phosphatases (PP1) have been described in the literature (figure, a) [42-52]. Epigenetic agents in the complexes can function cooperatively. Complex site-specific epigenetic rearrangements (figure, a) emerge as a result of coordinated work of various combinations of epigenetic agents creating "molecular brake pads" for individual target genes $[6,46,49]$. Interactions of a different set of epigenetic agents with molecules recognizing specific sites on the chromatin open possibilities for the fine tuning and effective regulation of the transcription of the specific target genes.

Class I histone deacetylases (HDAC I). It is well known from the literature that the representatives of HDAC I (HDAC1, 2, 3) are important elements of plasticity and memory mechanisms $[13,41]$. In vitro and in vivo experiments demonstrated that at rest HDAC in the composition of repressor complexes are associated with the promoter regions of some genes and suppress their transcription [13, 53-55]. However, the first question that the researchers face is how the specific epigenetic regulation of the individual genes of plasticity can be realized considering lack of the substrate specificity in histone deacetylases. There is no comprehensive answer to this question. The main information about HDAC characteristics was obtained in the studies of non-neuronal cell lines. According to the available data, HDACs do not bind directly to the DNA sequence, but are the central, catalytically active parts of various repressor complexes (Sin3A, NuRD, CoREST for HDAC1/HDAC2, and NCoR/SMRT for HDAC3) (figure, a), which seem to direct histone deacetylases towards the definite loci/sites of chromatin to control transcription of the specific genes $[13,41,42,45,55,56]$.

Using chromatin immunoprecipitation (ChIP) the distribution of HDAC1 and HDAC2 was analyzed in the mouse brain specimens in the promoter regions of certain genes some of which were not related to synaptic plasticity (Atf4, Pgk1, Gapdh, etc.), and protein products of other genes were believed to be specific regulators of morphology (NrxnI, Shank3, Synapsin2, PSD95, etc.), synaptic plasticity (GluR1/2, CamKIIa, Creb, Cbp, $\mathrm{PKM} \zeta$, etc.), or were regulated by the cellular activity (BDNF, Egr-1, c-Fos, Arc, etc.) [13]. It was found out that normally HDAC2 is bound with high selectivity (as compared with HDAC1) to the promoter regions of the majority of the above-mentioned specific genes [13]. Analysis of the HDAC1/2 interaction with the repressor complexes Sin3A, NuRD, and CoREST in the nuclear extracts revealed that only HDAC2 was associated with the chromatin remodeling complex CoREST. It suggests that being a part of the CoREST repressor complexes, HDAC2 interaction with the promoter regions of some plasticity-related genes restricts their expression at rest. Lack of the HDAC2 production in knockout animals resulted in the selective increase of the histone acetylation in the promoter regions of some plasticity-related genes that could not be compensated by the native HDAC1. It should be noted that the described mechanism hardly is the only one, and HDACs within other repressor complexes could participate in the fine tuning of operation of individual plasticity-related genes. As part of the NCoR/SMRT repressor complex, HDAC3 is specifically bound to the regulatory regions of some plasticity-related genes (Bdnf, Npas4, but not Fos), whereas most of the HDAC3 binding sites in the genome are localized in the intergenic and intragenic regions [55].

According to some data, interaction of HDAC I representatives with other epigenetic agents (see below), in particular with histone methyltransferase SUV39H1, facilitates delivery of the repressor complexes to chromatin regions for suppressing transcription of the individual genes [46]. This explains the observations that histone deacetylation and methylation are often coupled [6].

Class II histone deacetylases (HDAC IIa). Some representatives of the class IIa histone deacetylases (HDAC IIa) are especially interesting in connection with the mechanisms of plasticity, learning, and memory maintenance since they participate in the regulation of the transcriptional programs associated with structural changes in the synapses and efficiency of synaptic connections (HDAC4, HDAC5) [57-59].

The ability to translocate between the cytoplasm and nucleus depending on their phosphorylation state is the defining feature of HDAC IIa representatives, and this inevitably affects their ability to interact with the components of the repressor complexes and provides an additional level of spatial-temporal control of the gene expression (see further) [51]. In the spontaneously active cultures of neurons HDAC IIa histone deacetylases are distributed between the cytoplasmic (HDAC4) and nuclear (HDAC5) compartments [60, 61]. Physiological stimulation of neurons and increase in the concentration of intracellular calcium are factors, which stimulate phosphorylation of HDAC IIa (see further) and their export 
a

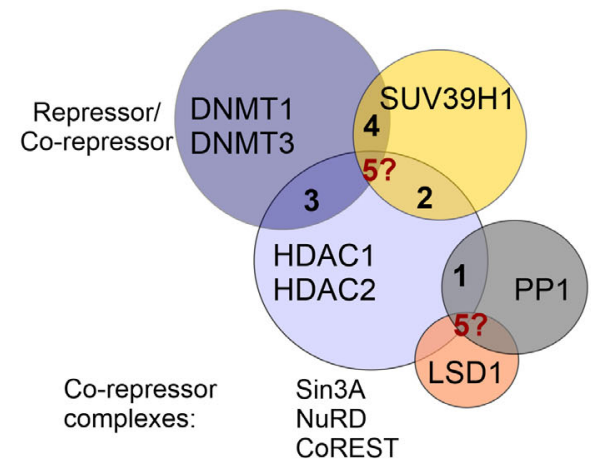

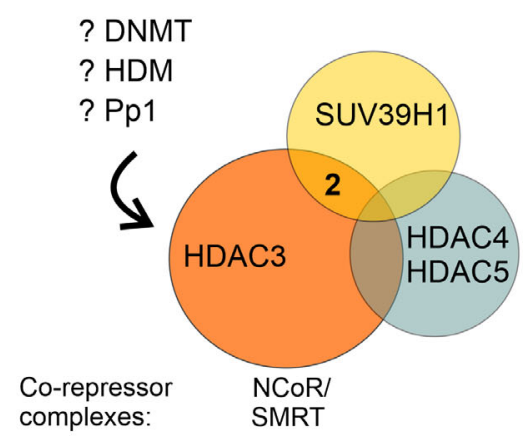

b

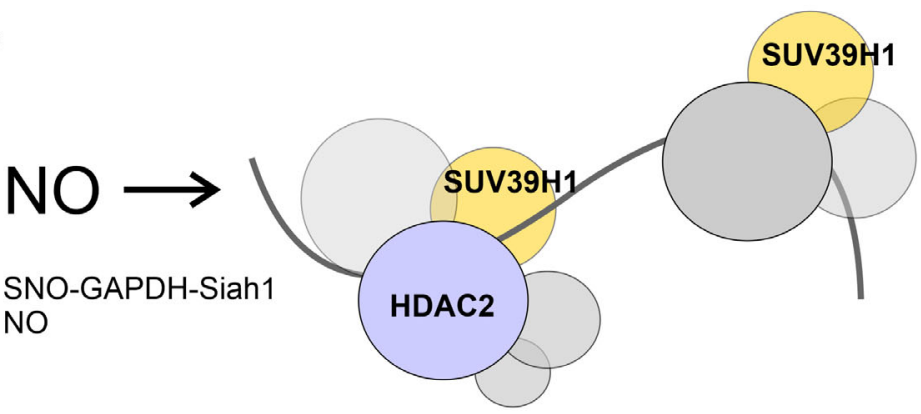

- Nitrosylation of HDAC2

results in its dissociation

from the chromatin

- Siah1 induces SUV39H1

degradation

c

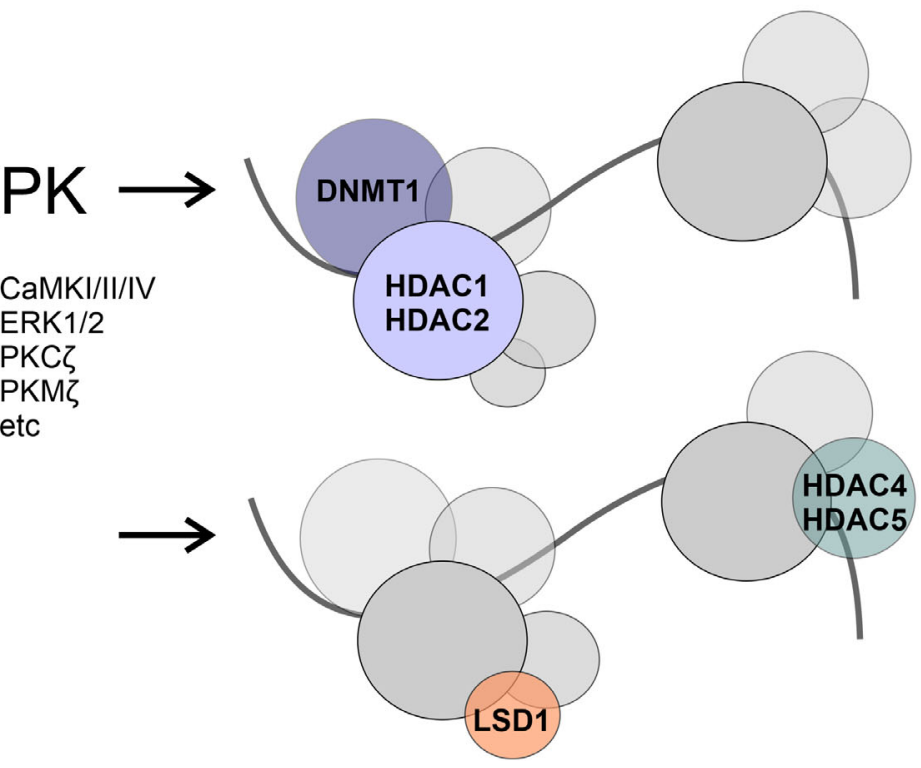

- Phosphorylation of HDAC1/2 and DNMT1 reduces their catalitic activity, and potentially affects the integrity of repressor complexes

- LSD1 phosphorylation leads to disassembly of repressor complexes

- Phosphorylation of HDAC4/5 induces their nuclear export, which affects the integrity of repressor complexes

Organization of repressor complexes and regulatory mechanisms of their association with chromatin (according to the data presented in the review). a) Schematic representation of possible combinations of repressor (HDAC, DNMT) and co-repressor proteins of different classes in the composition of the multiprotein repressor complexes. Possibility of protein-protein interaction between representatives of histone deacetylases (HDAC), DNA methyltransferases (DNMT), protein phosphatases (PP), histone demethylases (HDM, LSD1) and histone methyltransferases (SUV39H1) is presented as overlapping circles. Numbers indicate possible combinations of epigenetic rearrangements as a result of the coordinated work of corresponding repressor proteins (according to the literature data: 1 - deacetylation and dephosphorylation of histones; 2 - deacetylation and methylation of histones; 3 - deacetylation of histones and methylation of DNA; 4 - methylation of histones and DNA; 5 - more complicated possible combinations). $\mathrm{b}$ and c) Regulation of functions of components of the repressor complexes mediated through nitric oxide (NO) or protein kinases (PKs). Activation of neurons as a result of plastic changes is accompanied by translocation of PKs and newly synthesized NO molecules into the nucleus. As a result, components of the repressor complexes are subjected to the corresponding modifications (phosphorylation, nitrosylation), which affect their stability, activity, or intracellular localization. Temporary destabilization and dissociation of the multiprotein repressor complexes from the chromatin opens "the window of possibilities" for the changes of epigenetic profile and activation of the certain groups of plasticity-related genes. (Colored version of the figure is available in online version of the article and can be accessed at: https://www.springer.com/journal/10541) 
from the nucleus to the cytoplasm [60]. Suppression of the neuronal activity or treatment with the specific calcium-binding agents, on the contrary, stimulates the HDAC IIa translocation into the nucleus [58, 60, 61]. It was demonstrated that the balance shift towards the excessive content of HDAC IIa in the nucleus (under condition of overexpression of the phosphorylationresistant mutant isoform) was accompanied by the stimulus-dependent suppression of transcription of a number of the plasticity-related genes (Homer1, Arc, Npas4, Nr4a1, Egr2, etc.) [59, 61].

According to some data, the nuclear-cytoplasmic translocations of HDAC4/5 can play an important role in the formation of engrams and memory encoding [59]. Normally the engram size is fixed and allocation of the cells into the limited functional network is accompanied by a certain selection of neurons based, at least, on their excitability characteristics (regulating the activation level) during learning [62]. It seems that the level of neuron excitability influences the HDAC4/5 distribution between the nucleus and cytoplasm and determines what cells will be allocated into the functional network more effectively. This hypothesis was confirmed by the work of Zhu et al. [59] in which the HDAC4 distribution was analyzed immunohistochemically in the nuclei of neurons after learning. General increase in the HDAC4 content was shown in the nuclei of neurons, however, this was not the case for the potential engram cells, where the authors observed a very weak overlapping between the Fos-positive cells (marker of the engram neurons) and nuclear HDAC4. It was shown that disruption in the HDAC4/5 production prolonged the expression of some immediate early genes (up to $5 \mathrm{~h}$ ), increased the amount of Fos- and Egr1-positive cells (approximately 1.5-2 times), and was accompanied by the cognitive disorders in a series of behavioral tests. Taking into account other data of the authors, the HDAC4/5 activity actually limits the engram "size" (the number of neurons subjected to morphological and functional changes in response to external stimuli) through the spatial-temporal control of the gene transcription in the neurons.

The dephosphorylated HDAC IIa transported into the nucleus cannot directly bind to chromatin, specific interaction of their N-terminal fragment with the transcriptional factors and of the C-terminal region with corepressors facilitate attraction of the multiprotein complexes into the certain regions of chromatin $[44,51,56$, $58,63,64]$. The repressor functions of the naturally lowactive HDAC IIa (HDAC4/5) strongly depend on the selective interaction with enzymatically active representatives of HDAC I (HDAC3) in the composition of the multiprotein complexes NCoR/SMRT (figure, a) [44, 51, 56, 64].

A question arises about function of the low-active representatives of HDAC IIa in the active repressor complexes. It was shown that the loss of the catalytic domain of HDAC4 did not affect its brain functions associated with transcriptional regulation of the plasticity-related genes [58]. It can be suggested that the catalytically lowactive representatives of HDAC IIa could serve as a specific scaffold for attraction of other repressor proteins. Some data show that the binding of HDAC IIa (and of associated with them transcriptional factors) to the preexisting catalytically active HDAC3-NCoR/SMRT complexes provides the additional level of specificity at targeting of the produced complexes into the promoter regions of the genes [44]. It was found that the HDAC IIa (HDAC4/5) representatives could interact with the heterochromatin protein HP1, which could recognize and bind to the methylated $\mathrm{H} 3 \mathrm{~K} 9$ site on chromatin, and moreover, attract histone methyltransferase SUV39H1 [63]. Co-localization of HDAC IIa with SUV39H1 in the multiprotein complexes (figure, a), as well as the abovepresented data on the interaction of HDAC IIa/HDAC I and SUV39H1/HDAC I, could provide explanation for the functional association of histone deacetylation and methylation processes, assuming cooperative action of the mentioned repressor complexes, or even existence of the higher order repressor complexes [6, 44, 46, 56, 63].

DNA methyltransferases (DNMT). Representatives of the family of DNA methyltransferases (DNMT) are thought to play a special and rather important role in the plasticity and memory mechanisms: they are thought to be responsible for maintenance of the existent methylation status of DNA regions (DNMT1) and for de-novo DNA methylation (DNMT3a, DNMT3b) [21, 24, 52, 65]. According to the literature data, plastic processes in the nervous system are associated with the shift of the existent balance towards DNA methylation in the promoters of the memory suppressor genes (phosphatases Ppp 1cc, Ppp3ca), and simultaneous rapid demethylation of the promoters of the plasticity-related genes (Reln) [21, 65].

Considering the data on a relatively low selectivity of DNMT, a question emerges on how the specific methylation pattern can be generated in the specific DNA sequences of the genes. DNMT can be attracted into the definite loci based on the local epigenetic landscape, because the appearance of the histone methylation marks in the regions of inactive chromatin often precedes DNA methylation [66]. It was shown that recognition of the repressive histone marks by de-novo methyltransferases (DNMT3) occurs via their N-terminal domain [52, 67]. Moreover, DNMT can be attracted into the corresponding chromatin regions indirectly, via interaction with histone methyltransferases (SUV39H1, figure, a) and other regulatory molecules [49, 66-68].

For effective control of the gene transcription, there are the histone deacetylase (HDAC1/2) binding sites in the N-terminal fragments of DNMT molecules [43, 47, $49,52]$. DNA methyltransferases can cooperate with each other and with HDAC1 (figure, a) producing the multi- 
protein repressor complexes in the promoter regions of individual genes [49]. Some data indicate that HDACs play a central role in such complexes, because the corepressive functions of the DNMT3 family representatives can be realized independent on the functional integrity of their catalytic domain [43, 47]. Moreover, nonspecific inhibitors of HDAC are sufficient for dissociation of the DNMT/HDAC repressor complexes from the promoter regions and activation of transcription of the corresponding target genes [43, 49]. It was shown that the removal of the "molecular brake pads" in the promoter regions of the target genes was accompanied by the decrease in the DNA methylation and increase in the histone acetylation [49].

Analysis of the literature data does not reveal casual relationship in the DNMT-HDAC interaction. On the one hand, DNA methylation in the definite loci can serve as a signal for attracting the HDAC-associated repressor complexes and condensation of chromatin that preserves the corresponding genes in the repressed state. On the other hand, the presence of HDAC/HMT-containing complexes of chromatin remodeling can provide a certain epigenetic landscape in the chromatin regions, which would facilitate recognition by the different DNA methyltransferases, creation of the DNA methylation marks, and suppression of the transcriptional activity of the genes. In any case, induction of the high-order epigenetic rearrangements due to coordinated work of the HDAC/HMT/DNMT-containing complexes potentially can provide an effective transcriptional control of the corresponding target genes: presumably, downregulation of the memory suppressor genes and activation of some plasticity-related genes.

Nitrosylation as a tool for removal of "molecular brake pads". Nitric oxide (NO) can act as a modulator of the epigenetic landscape in various cells [69]. Although there are data available on participation of NO in realization of the memory mechanisms in vertebrates and invertebrates, the NO-dependent long-term plasticity has not been actively discussed in the context of epigenetic regulation of the genes [70, 71]. According to some very few data, physiological stimulation of the cells and increase in the intracellular calcium level led to activation of the neuronal NO-synthase (nNOS) and production of NO, which was accompanied by S-nitrosylation of the protein targets, NO-dependent chromatin rearrangements, and activation of expression of the plasticity-related genes (see further).

Contrary to the generally accepted opinion that NO effects are not specific, only 614 potential protein targets for the NO-dependent S-nitrosylation were identified by proteomic analysis in the nuclear extracts of the cortical neurons among the 3078 proteins [72]. The list of targets for nitrosylation includes some histone deacetylases (HDAC1/2), subunits of co-repressor complexes ( $\operatorname{Sin} 3 \mathrm{a}$, NuRD), PPs (PP1, PP2A), transcription factors (CREB,
YY1), and other nuclear proteins involved in reorganization of the chromatin structure and transcriptional regulation $[53,54,72,73]$. The nitrosylated fragments of protein targets were analyzed by liquid chromatography and tandem mass spectrometry methods and unique motifs corresponding to the nitrosylation sites were identified [72]. In the majority of cases, there are no data available on the effect of nitrosylation on the functions of protein targets under physiological conditions. It is very likely that nitrosylation can be a destabilizing factor (in the case of repressor complexes with HDAC2), as well as a stabilizer of some protein complexes (in the case of GAPDH-Siah1 complexes) (see further).

It was shown in vitro that physiological stimuli $\left(\mathrm{Ca}^{2+}\right.$, BDNF, NMDA, $\mathrm{KCl}$ ) induced production of NO associated with $\mathrm{S}$-nitrosylation of some protein targets (HDAC2, CREB, figure, b) in the neurons and in nonneuronal cells [54, 72, 73]. Nitrosylation of HDAC2 at certain sites in the conservative catalytic domain does not affect the enzyme activity, but, apparently due to conformational rearrangements, leads to dissociation of HDAC2 from the complexes with chromatin in promoter regions of some plasticity-related genes (Fos, Egrl, Vgf, Nos 1) and provides conditions for binding transcriptional activators [54]. It was shown that NO induces nitrosylation of the C-terminal DNA-binding domain of the transcriptional factor CREB [72] and its binding to the promoter regions of the target genes [53]. As a result, the stimulus-dependent binding of HAT CBP to CREB led to the increase in the histone acetylation and initiation of transcription of the CREB-dependent genes [53, 54].

Similar data were obtained in vivo in behavioral experiments. Studies on the recent memory reactivation in mice revealed the enrichment of the acetylated histone marks in the CA1 region of the hippocampus, in particular, in the promoter region of the plasticity-related gene Fos that was associated with nitrosylation of HDAC2 and release of histone deacetylase from the complexes with chromatin (figure, b) [71]. It is interesting that duration of the HDAC2 nitrosylation correlates with the critical time window of the memory reconsolidation (about $6 \mathrm{~h}$ ) [71], which confirms the earlier proposed hypothesis about the HDAC functioning as "molecular brake pads" during the plastic changes in the nervous system [41]. Additional experiments provide reason to believe that the recent memory reactivation is associated with temporary labialization of the memory partially caused by the NOdependent S-nitrosylation of HDAC2, increase in the histone acetylation, and induction of the plasticity-related gene transcription [71]. The results are in agreement with other studies on the role of NO in the memory labialization during its reconsolidation [70].

Comparison of the dynamics of molecular processes in the hippocampus of mice in the study on the recent and remote memory revealed the NO-dependent regulation of the epigenetic landscape in the first case and absence of 
the regulation in the second case [71]. The observed differences seem to be associated with the changes in involvement of the hippocampal networks in formation of the recent and remote memory [29]. It cannot be ruled out that investigation of the remote memory in active engrams of the prefrontal cortex could reveal molecular changes similar to those described for hippocampus.

Existence of the nuclear function of NO under physiological conditions could be accepted with some skepticism considering information about the nNOS localization far from the nucleus, instability of the produced NO molecules (their lifetime is only few seconds) and, as a consequence, unavailability of the nuclear proteins for $\mathrm{S}$ nitrosylation. However, the use of the NO-binding fluorescent label revealed rapid accumulation of $\mathrm{NO}$ in the cytoplasm and nucleus [54]. The possibility of NO accumulation in the nucleus was reported in another work dedicated to studying the process of protein-protein transnitrosylation as a mechanism of selective "transfer" of NO groups onto some nuclear proteins [73]. The authors found that the cytoplasmic GAPDH proteins were nitrosylated (SNO-GAPDH) and in this form were transported into the nucleus in complexes with the proteins Siah1 carrying nuclear localization signals (figure, b). It was proven experimentally that SNO-GAPDH serve as physiological sources of NO groups for selective nitrosylation of the nuclear proteins - targets of GAPDH (HDAC2, SIRT1), but not of the cytoplasmic proteins ( $\beta$-tubulin). The presented scheme of the specific protein-protein "transfer" of NO groups could be probably realized with participation of other protein "carriers" and is a rather common element of the physiological and pathological signaling cascades in the nerve cells [72, 74]. It seems that the influence of nitrosyl complexes is not limited to the regulation of histone acetylation, but can also affect histone methylation. The elements of nitrosylated complexes (Siah1) found in the nucleus can cause degradation of SUV39H1 (figure, b) in the activated cortical neurons, which is manifested by the decrease in the number of $\mathrm{H} 3 \mathrm{~K} 9 \mathrm{me} 3$ repressive marks and facilitates the CREB-dependent gene transcription [75].

Phosphorylation as a tool to control "molecular brake pads". Maintenance of a certain level of phosphorylation of cellular targets due to coordinated work of different protein kinases (PKs) and protein phosphatases (PPs) is an integral component of plastic and cognitive processes in the nervous system $[25,40,48,76-78]$. In the framework of this review we will not focus on the important synaptic functions of PKs and PPs, but will try to present some examples on how different representatives of these groups in neurons and other cells operate on the chromatin level directly (histone phosphorylation), as well as indirectly via changes in the work of various epigenetic agents [48, 77, 79, 80].

Role of phosphatases in stabilization of "molecular brake pads". It has been shown that the balance between the work of PKs and PPs is established to stabilize "molecular brake pads". Under rest conditions nuclear phosphatases (PP1, PP4) in neurons and non-neuronal cells interact with different histone deacetylases (HDAC1/2, HDAC3) and histone demethylases (LSD1) forming stable and enzymatically active repressor complexes on the chromatin (figure, a) [45, 48, 50, 81, 82]. Cytoplasmic phosphatases (PP2A) in inactive non-neuronal cells dephosphorylate representatives of HDAC IIa that serves as a signal for their translocation from the cytoplasm into the nucleus and facilitates interaction with the nuclear repressor proteins [51, 64].

According to some data, the formed multiprotein repressor complexes consisting of histone deacetylases (HDAC I, HDAC IIa), phosphatases, and histone demethylases (figure, a) can work cooperatively to stabilize "molecular brake pads" and suppress transcription of the plasticity-related genes under rest conditions. It was shown for the mouse brain specimens that the presence of PP1 phosphatase in the promoter regions of some plasticity-related genes $(C R E B, N f k b 1)$ had a negative correlation with some active site-specific modifications of chromatin (phosphorylation, acetylation, methylation) that affected transcriptional activity of the corresponding genes $[48,77]$. Loss/decrease of enzymatic activity of any of the components (PP1, HDAC I, LSD1) was accompanied by destabilization of the repressor complexes and their dissociation from chromatin, in other words, by the removal of "molecular brake pads" from the specific target genes [45, 48, 50, 77, 81]. Suppression of the PP1 activity in vivo in the brain of transgenic mice correlated with the drop of deacetylase activity in the nucleus and enrichment of active histone marks in some regions of the brain $[25,48,77]$. The obtained data explain how administration of inhibitors of either histone deacetylases or PPs in electrophysiological and behavioral experiments leads to similar changes in the synaptic plasticity and efficiency of learning [77, 83].

Chronic disruption of dephosphorylation of epigenetic targets in vitro in the cultures of cortical neurons and in vivo in brain specimens from transgenic mice was accompanied by the changes in expression of a spectrum of genes [50, 84]. In particular, expression was decreased in the group of genes involved in the transmembrane signal transduction and in metabolic processes, whereas the entire clusters of genes associated with transcription/ translation and intercellular communications were activated [84]. These data are in a good agreement with the results of behavioral experiments when in $24 \mathrm{~h}$ after the learning an increase was observed in the expression of genes involved in the synaptic transmission, as well as a decrease in the expression of genes - regulators of metabolic processes [20]. These data give an indication of the cellular processes affected during the changes in the balance of phosphorylation and possibly imply participation of phosphatases in the normal maintenance of metabolic 
transcriptome (homeostasis). The shifted balance towards phosphorylation of the targets, on the contrary, facilitates switching on the plastic transcriptome.

Role of protein kinases in destabilization of "molecular brake pads" and stimulus-dependent induction of epigenetic rearrangements. Plastic processes in the nervous system are associated with activation and nuclear translocation of different PKs; an active import of some PKs (CaMKI $\delta$, Erk, $\mathrm{PKC} \zeta, \mathrm{PKM} \zeta$ ) into the nucleus in response to physiological stimuli was observed in neurons and non-neuronal cells [80, 85-88]. The time dynamics of nuclear translocations vary significantly for different PKs that can indicate the differences in their substrate specificities [80, $86,88]$. PKs transported into the nucleus could play a special role in the molecular mechanisms of learning and memory realizing the selective control of the spatial and temporal epigenetic landscape and expression of the certain genes.

The stimulus-specific phosphorylation of epigenetic regulators induces conformational changes leading to the loss of enzymatic activity (HDAC I, DNMT1) or changes in the intracellular localization (HDAC IIa) of repressor proteins, temporary destabilization of the corresponding repressor complexes and removal of the "molecular brake pads" (figure, c). At present part of the data are obtained for the non-neuronal cells, nevertheless, similar principle of regulation could be also realized in neurons. It was shown that hyperphosphorylation of $\mathrm{HDACl} / 2$ was accompanied by the decrease of deacetylase activity and led to disruption of $\mathrm{HDAC} 1 / 2$ bonds with co-repressor proteins or transcriptional factors and dissociation of HDAC1/2 from the chromatin (figure, c) [45]. Phosphorylation of the histone demethylase LSD1 in neurons does not affect its enzymatic activity, but is accompanied by conformational changes and destabilization of the complexes of LSD1 with repressor proteins HDAC1/2 and CoREST (figure, c). [50]. There are some data available indicating that phosphorylation sites are present in the DNMT sequences, which in combination with a few experimental data make them potential PK targets $[52,67,89]$. In the framework of our review, the work of Lavoie et al. [89] is especially interesting: in this work some representatives of the PKC family were demonstrated to be able to modify DNMT1. Phosphorylation of DNMT1 under the influence of PKC $\zeta$ causes decrease in its enzymatic activity (figure, c) and is accompanied by the general reduction in the level of DNA methylation in the promoter regions of some genes in non-neuronal cells. Based on the presented data, we assume that the stimulus-dependent transport of PKs (PKC $\zeta$ and, possibly, other isoforms) into the nucleus can lead to the decrease in methyltransferase activity of DNMT, changes in the DNA methylation profile, and modulation of the gene expression in the active neurons.

The stimulus-dependent phosphorylation of HDAC IIa representatives by the activated $\mathrm{Ca}$-dependent kinases
(CaMK I, II, IV; Erk1/2) leads to disruption of the HDAC IIa interaction with other repressor proteins and to their export from the nucleus into the cytoplasm (figure, c) thus restricting delivery of the repressive HDAC IIa molecules to the target genes [51, 60, 61, 63].

Thus, the temporary stimulus-specific destabilization of repressor complexes associated with the decrease in activity or change in intracellular localization of the repressor proteins in their composition opens "the window of possibilities" for inducing epigenetic rearrangements and transcriptional activation of the target genes. It was shown that in response to the cell depolarization and increase in the calcium concentration, PKs transported into the nucleus could stimulate phosphorylation of histones [79] and components of the activator complexes, in particular, of some transcriptional factors (CREB, C/EBP, Elk1) and HAT [80, 86, 87, 90-93]. According to some data, phosphorylation can facilitate interaction of the transcriptional factors (TF) with their co-activators HAT [94]. Some studies have shown that phosphorylation of CREB is not required for the CREB-dependent gene transcription; phosphorylation of HAT CBP becomes the limiting factor of activation of the CREB-CBP signaling cascade as the organism grows older [93, 95]. In some works, it was established that HAT CBP could serve as a target for the site-specific phosphorylation by a number of PKs (CaMKIV, MAPK, representatives of aPKC), and in complexes with the transcription factors CREB or Elk1 the phosphorylated CBP activates transcription of the corresponding genes/reporter constructs [80, 91-93, 96].

In terms of the plastic processes and memory mechanisms, the components of the CREB-CBP signaling pathway are the most interesting among many targets [83, 97]. We have noticed during the literature analysis that the majority of studies on neurons and non-neuronal cells revealed the key, though not the exclusive role of atypical PKs (aPKC) in the regulation of CBP functions [80, 91, 92]. A binding site for atypical PKs (Ser436) was found in CBP sequence, which underwent phosphorylation by PKs PKCi in the peripheral tissues [91] and by PKs $\mathrm{C} \zeta / \mathrm{M} \zeta$ in the brain $[80,92,93]$ in response to certain stimuli. Phosphorylation at the Ser436 site is crucial for recruiting $\mathrm{CBP}$ into the promoter regions of the target genes, interaction with CREB, and induction of chromatin rearrangements $[80,92,93]$. It was shown that the aPKC-dependent phosphorylation in the developing brain led to binding of CBP to the promoter regions of some developmental genes and regulation of differentiation of the precursor cells in the cortical area [92]. In the adult brain, the aPKC-CBP signaling pathway controls neurogenesis and is vital for formation and long-term maintenance of the hippocampus-dependent memory [93]. These data are in agreement with the results of experiments in vertebrates and invertebrates in which the memory impairment caused by injection of aPKC inhibitors can be compensated by the HDAC inhibitors 
due to disruption of re-association of the repressor complexes and stimulation of histone acetylation [80, 98].

The presented data demonstrate that PKs serve as the most important link between the activity-dependent synaptic changes on the cell periphery and processes occurring in the nucleus. Activation of the cells and subsequent increase in the calcium levels stimulate the transport of some PKs into the nucleus, where the chromatin-bound protein regulators are phosphorylated in the activity-dependent manner (figure, c), "molecular brake pads" are removed for a short time, and formation of activator complexes is facilitated. The linked emergence of various active histone marks during the memory formation and/or retrieval can be the result of interaction between the nuclear PKs and TF-HAT on chromatin, when the neighboring histones are subjected to the double influence: acetylation by activated HAT and phosphorylation by the corresponding PKs [25, 48, 79]. Complex chromatin rearrangements and attraction of activator molecules result in the activation of certain transcriptional programs directed to change efficiency of the synaptic connections, and changes in the "status" of the activated neurons in the network. It is likely that shutting off the "critical window" for the plasticity and restoration of the basic characteristics in the promoter regions of the target genes are coordinated by the newly assembled repressor complexes.

\section{MEMORY: WHAT REMAINS AFTER THE LEARNING}

Structural changes in chromatin (post-translational histone modifications) are integral components of the processes associated with the memory formation. Removal of molecular brakes opens the "critical window" for global plastic changes, triggering specific transcriptional programs and modulation of the effectiveness of synaptic connections (see above). In particular, this was confirmed by the RNA-sequencing data for the small group of cells and fragments of hippocampus: it was shown that the learning was accompanied by specific changes in the expression of entire clusters of the late genes associated with the synaptic functions or encoding of receptor subunits and ion channels [20, 99]. The reversible character of post-translational histone modifications that does not exclude retention of some rather local rearrangements in the regulatory regions of individual genes has been discussed in the literature, but the question about approaches for the long-term maintenance of plastic changes on the certain level still remains open $[25,26,79]$.

Based on the results of sequencing, we think that the key for answering this question could be the processes associated with the stimulus-specific changes and preservation of a certain DNA methylation profile in the indi- vidual intergenic, intragenic, and promoter regions of the genes until the next stimulus-specific removal of the "molecular brake pads" (e.g., reminder) [3, 20]. The most important role of DNA methylation in the plasticity mechanisms was illustrated in invertebrates in which the researchers could artificially form the specific memory trace in the untrained mollusks Aplysia by injections of RNA fractions isolated from the nervous system of the trained animals [100]. Injection of factors (presumably the non-coding RNAs) present in the neurons of the trained animals generated a certain pattern of DNA methylation, a kind of "epigenetic engram", which can be destroyed by injecting DNMT inhibitors. It was shown for mammals that the increase in production of DNA methyltransferase DNMT3a2 in the specific functional neural networks stimulated changes in the methylation profile of the synaptic plasticity genes and increased the stability of this engram at the memory retrieval (see above) [24]. Miller et al. [21] went further and managed to destroy the established DNA methylation profile in the prefrontal cortex of rats 30 days after the learning using DNMT inhibitors. Local injection of the DNMT inhibitor affected the gene expression profile and led to disruptions in the maintenance of the remote memory.

The detailed consideration showed that the methylation profile of DNA in certain chromatin regions controlled the possibility of binding the CTCF factor - key regulator of the chromatin 3D organization [101]. Due to interaction with the distant regions of DNA and formation of loops, CTCF can bring together the regulatory regions of the genome (enhancers, insulators) with the sites of the target genes and modulate the level of their expression [102]. It was shown that CTCF was specifically involved in the regulation of expression of the plasticity-related genes in the hippocampus and prefrontal cortex [103, 104]. Studies on the CTCF influence on the recent hippocampus-dependent memory produced contradictory results, which prevented an unambiguous conclusion, but did not ruled out the possible role of CTCF in the hippocampus under certain conditions [103, 104]. Genetic manipulations with amounts of CTCF in the excitatory and inhibitory neural networks in the prefrontal cortex demonstrated crucial role of this factor in regulation of the synaptic plasticity and long-term (4 weeks) maintenance of the memory [104]. Suppression of the CTCF production led to the changes in the basal expression of different groups of genes [103, 104]. The data obtained allow us to suggest that CTCF supports the definite 3D organization of chromatin, which is associated with low-level basal expression of such targets as HDAC3 and HDAC7 [103]. Moreover, the stimulus-specific increase in the expression of the memory suppressor genes (Ppp 1c), as well as altered expression of some plasticity-related genes (Arc, Bdnf, Reln) were observed in the hippocampus of CTCF-deficient mice during the learning [103]. Altered expression of the plasticity-related 
genes under conditions of CTCF deficiency could be associated with the changes in the chromatin architecture in these loci, which are manifested by the loss of some CTCF-dependent contacts between the genes Arc and $B d n f$ and other sites on the chromosome [103].

The obtained data suggest that the character of DNA methylation in the definite chromatin loci and methylation-dependent types of its $3 \mathrm{D}$ organization can serve a stable molecular basis for realization of certain transcriptional programs required for regulation of plasticity and maintenance of memory for an indefinitely long time.

\section{CONCLUSIONS}

The search for specific mechanisms of controlling cognitive processes under normal conditions and in pathology is quite urgent in the framework of modern neurobiology. Currently, attention of the researchers is focused on the molecular processes in the nucleus, since changes in the genome functioning form the basis for the adaptive functions of the organism, including learning and memory. In the present review, we tried to summarize the data accumulated in literature and consider in detail the prerequisites and mechanisms of epigenetic rearrangements, which could provide specific control of gene functioning at the network and cellular levels. Various epigenetic agents in the composition of the highorder multiprotein repressor complexes operate on the chromatin, cooperatively acting as the "molecular brake pads", selectively preserving low expression level of the plasticity-related genes at rest (see above). Activation of neurons in response to physiologically relevant stimuli triggers a series of biochemical events (phosphorylation, nitrosylation), which result in a temporary removal of the "molecular brake pads" and opening of the "critical window" for global and local epigenetic rearrangements, activation of specific transcriptional programs, and modulation of the efficiency of synaptic connections (see above). A rather difficult question for us is how the system of specific "navigation" of epigenetic agents is arranged and how they are attracted into the regulatory regions of the certain groups of genes. In this review, we attempted to provide some information regarding this problem, but it is our opinion that that the future studies should involve detailed consideration of the role of various groups of non-coding RNAs present in huge amounts in the nerve tissue. According to published data, the non-coding RNAs, which are still poorly understood, could contribute to the changes of epigenetic landscape and serve as the most important element of the fine tuning of functioning of certain genes, including the plasticity-related genes [105].

Another equally very important issue is elucidation of the stable molecular basis for maintaining and storage of the corresponding plastic changes, i.e., the memory. To date, all researchers unanimously believe that DNA methylation is the final and the most resistant system for storage of information in the cell [3,21,24]. This concept becomes more complicated with increase of data. Fragmentary information allows us to think that preservation of a certain spatial organization of chromatin, which is a methylation-dependent process, is critical for maintaining the transcriptional programs [103, 104]. It is possible that the stimulus-dependent methylation of DNA provokes changes in the cytoarchitecture of chromatin which "locks" some or other genes in the certain functional state, however, such assumptions require special detailed investigation.

Experimental data obtained for the model organisms demonstrate that establishing the epigenetic mechanisms controlling the gene activity is promising. A new line of investigations is in progress, allowing selective editing of epigenome [106]. The development of techniques and systems for epigenome editing is very promising for studying brain development, cognitive functions, and correction of neuropathologies caused by abnormal gene activity. Implementation of such technologies seems to be a logical continuation of the current studies, because it can provide a new level of understanding of the specific mechanisms regulating neuroplasticity and memory.

Funding. The reported study was funded by the Russian Foundation for Basic Research (project no. 19115-50290).

Ethics declarations. The authors declare no conflict of interest in financial or any other sphere. This article does not contain any studies with human participants or animals performed by any of the authors.

Open access. This article is distributed under the terms of the Creative Commons Attribution 4.0 International License (http://creativecommons.org/licenses/ by/4.0/), which permits unrestricted use, distribution, and reproduction in any medium, provided you give appropriate credit to the original author(s) and the source, provide a link to the Creative Commons license, and indicate if changes were made.

\section{REFERENCES}

1. Alberini, C. M., and Kandel, E. R. (2014) The regulation of transcription in memory consolidation, Cold Spring Harb. Perspect. Biol., 7, a021741, doi: 10.1101/cshperspect. a021741.

2. Kyrke-Smith, M., and Williams, J. M. (2018) Bridging synaptic and epigenetic maintenance mechanisms of the engram, Front. Mol. Neurosci., 11, 369.

3. Halder, R., Hennion, M., Vidal, R. O., Shomroni, O., Rahman, R. U., Rajput, A., Centeno, T. P., van Bebber, F., Capece, V., Garcia Vizcaino, J. C., Schuetz, A. L., Burkhardt, S., Benito, E., Navarro Sala, M., Javan, S. B., 
Haass, C., Schmid, B., Fischer, A., and Bonn, S. (2016) DNA methylation changes in plasticity genes accompany the formation and maintenance of memory, Nat. Neurosci., 19, 102-110.

4. Jarome, T. J., and Lubin, F. D. (2014) Epigenetic mechanisms of memory formation and reconsolidation, Neurobiol. Learn. Mem., 115, 116-127.

5. Penney, J., and Tsai, L. H. (2014) Histone deacetylases in memory and cognition, Sci. Signal., 7, re12, doi: 10.1126/ scisignal.aaa0069.

6. Kim, S., and Kaang, B. K. (2017) Epigenetic regulation and chromatin remodeling in training and memory, Exp. Mol. Med., 49, e281.

7. Montarolo, P. G., Goelet, P., Castellucci, V. F., Morgan, J., Kandel, E. R., and Schacher, S. (1986) A critical period for macromolecular synthesis in long-term heterosynaptic facilitation in Aplysia, Science, 234, 1249-1254.

8. Guan, Z., Giustetto, M., Lomvardas, S., Kim, J. H., Miniaci, M. C., Schwartz, J. H., Thanos, D., and Kandel, E. R. (2002) Integration of long-term-memory-related synaptic plasticity involves bidirectional regulation of gene expression and chromatin structure, Cell, 111, 483-493.

9. Ganai, S. A., Ramadoss, M., and Mahadevan, V. (2016) Histone deacetylase (HDAC) inhibitors - emerging roles in neuronal memory, training, synaptic plasticity and neural regeneration, Curr. Neuropharmacol., 14, 55-71.

10. Latcheva, N. K., Viveiros, J. M., Waddell, E. A., Nguyen, P. T. T., Liebl, F. L. W., and Marenda, D. R. (2018) Epigenetic crosstalk: pharmacological inhibition of HDACs can rescue defective synaptic morphology and neurotransmission phenotypes associated with loss of the chromatin reader Kismet, Mol. Cell. Neurosci., 87, 77-85.

11. Toropova, K. A., Anokhin, K. V., and Tiunova, A. A. (2014) The blockade of histone deacetylation in the brain modulates the expression of the transcription factors c-Fos and ZENK and potentiates the formation of long-term memory in newborn chicks, Zh. Vyssh. Nerv. Deiat. I. P. Pavlova, 64, 551-561.

12. Zuzina, A., Vinarskaya, A., and Balaban, P. (2020) Histone deacetylase inhibitors rescue the impaired memory in terrestrial snails, J. Compar. Physiol. A., 206, 639-649, doi: 10.1007/s00359-020-01422-w.

13. Guan, J. S., Haggarty, S. J., Giacometti, E., Dannenberg, J. H., Joseph, N., Gao, J., Nieland, T. J., Zhou, Y., Wang, X., Mazitschek, R., Bradner, J. E., DePinho, R. A., Jaenisch, R., and Tsai, L. H. (2009) HDAC2 negatively regulates memory formation and synaptic plasticity, Nature, 459, 55-60.

14. Morris, M. J., Mahgoub, M., Na, E. S, Pranav, H., and Monteggia, L. M. (2013) Loss of histone deacetylase 2 improves working memory and accelerates extinction training, J. Neurosci., 33, 6401-6411.

15. Vanyushin, B. F., Tushmalova, N. A., and Guskova, L. V. (1974) Methylation of brain DNA as an indicator of genome involvement in the mechanisms of individually acquired memory, Doklady AN SSSR, 219, 742-744.

16. Guskova, L. V., Burtseva, N. N., Tushmalova, N. A., and Vanyushin, B. F. (1977) The level of DNA methylation in the nuclei of neurons and glia of the cerebral hemisphere cortex of the rat brain and its changes during the development of a conditioned reflex, Doklady AN SSSR, 233, 993996.
17. Holliday, R. (1999) Is there an epigenetic component in long-term memory? J. Theor. Biol., 200, 339-341.

18. Day, J. J., and Sweatt, J. D. (2010) DNA methylation and memory formation, Nat. Neurosci., 13, 1319-1323.

19. Pearce, K., Cai, D., Roberts, A. C., and Glanzman, D. L. (2017) Role of protein synthesis and DNA methylation in the consolidation and maintenance of long-term memory in Aplysia, Elife, 6, e18299.

20. Duke, C. G., Kennedy, A. J., Gavin, C. F., Day, J. J., and Sweatt, J. D. (2017) Experience-dependent epigenomic reorganization in the hippocampus, Learn. Mem., 24, 278288.

21. Miller, C. A., Gavin, C. F., White, J. A., Parrish, R. R., Honasoge, A., Yancey, C. R., Rivera, I. M., Rubio, M. D., Rumbaugh, G., and Sweatt, J. D. (2010) Cortical DNA methylation maintains remote memory, Nat. Neurosci., 13, 664-666.

22. Gupta, S., Kim, S. Y., Artis, S., Molfese, D. L., Schumacher, A., Sweatt, J. D., Paylor, R. E., and Lubin, F. D. (2010) Histone methylation regulates memory formation, J. Neurosci., 30, 3589-3599.

23. Lesburguères, E., Gobbo, O. L., Alaux-Cantin, S., Hambucken, A., Trifilieff, P., and Bontempi, B. (2011) Early tagging of cortical networks is required for the formation of enduring associative memory, Science, 331, 924928.

24. Gulmez Karaca, K., Kupke, J., Brito, D. V. C., Zeuch, B., Thome, C., Weichenhan, D., Lutsik, P., Plass, C., and Oliveira, A. M. M. (2020) Neuronal ensemble-specific DNA methylation strengthens engram stability, Nat. Commun., 11, 639.

25. Gräff, J., Woldemichael, B. T., Berchtold, D., Dewarrat, G., and Mansuy, I. M. (2012) Dynamic histone marks in the hippocampus and cortex facilitate memory consolidation, Nat. Commun., 3, 991.

26. Gupta-Agarwal, S., Franklin, A. V., Deramus, T., Wheelock, M., Davis, R. L., McMahon, L. L., and Lubin, F. D. (2012) G9a/GLP histone lysine dimethyltransferase complex activity in the hippocampus and the entorhinal cortex is required for gene activation and silencing during memory consolidation, J. Neurosci., 32, 5440-5453.

27. Sui, L., Wang, Y., Ju, L. H., and Chen, M. (2012) Epigenetic regulation of reelin and brain-derived neurotrophic factor genes in long-term potentiation in rat medial prefrontal cortex, Neurobiol. Learn. Mem., 97, 425-440.

28. Webb, W. M., Sanchez, R. G., Perez, G., Butler, A. A., Hauser, R. M., Rich, M. C., O’Bierne, A. L., Jarome, T. J., and Lubin, F. D. (2017) Dynamic association of epigenetic H3K4me3 and DNA 5hmC marks in the dorsal hippocampus and anterior cingulate cortex following reactivation of a fear memory, Neurobiol. Learn. Mem., 142, 66-78.

29. Kitamura, T., Ogawa, S. K., Roy, D. S., Okuyama, T., Morrissey, M. D., Smith, L. M., Redondo, R. L., and Tonegawa, S. (2017) Engrams and circuits crucial for systems consolidation of a memory, Science, 356, 73-78.

30. Borodinova, A. A., and Salozhin, C. V. (2016) Differences of the biological functions of BDNF and proBDNF in the central nervous system, Zh. Vyssh. Nerv. Deiat. I. P. Pavlova, 66, 3-23.

31. Bosch, C., Muhaisen, A., Pujadas, L., Soriano, E., and Martínez, A. (2016) Reelin exerts structural, biochemical and transcriptional regulation over presynaptic and postsy- 
naptic elements in the adult hippocampus, Front. Cell. Neurosci., 10, 138.

32. Valiati, F. E., Vasconcelos, M., Lichtenfels, M., Petry, F. S., de Almeida, R. M. M., Schwartsmann, G., Schröder, N., de Farias, C. B., and Roesler, R. (2017) Administration of a histone deacetylase inhibitor into the basolateral amygdala enhances memory consolidation, delays extinction, and increases hippocampal BDNF levels, Front. Pharmacol., 8, 415.

33. Hermey, G., Mahlke, C., Gutzmann, J. J., Schreiber, J., Blüthgen, N., and Kuhl, D. (2013) Genome-wide profiling of the activity-dependent hippocampal transcriptome, PLoS One, 8, e76903.

34. Benito, E., and Barco, A. (2015) The neuronal activitydriven transcriptome, Mol. Neurobiol., 5, 1071-1088.

35. Fowler, T., Sen, R., and Roy, A. L. (2011) Regulation of primary response genes, Mol. Cell, 44, 348-360.

36. Herschman, H, R. (1991) Primary response genes induced by growth factors and tumor promoters, Annu. Rev. Biochem., 60, 281-319.

37. Tyssowski, K. M., DeStefino, N. R., Cho, J. H., Dunn, C. J., Poston, R. G., Carty, C. E., Jones, R. D., Chang, S. M., Romeo, P., Wurzelmann, M. K., Ward, J. M., Andermann, M. L., Saha, R. N., Dudek, S. M., and Gray, J. M. (2018) Different neuronal activity patterns induce different gene expression programs, Neuron, 98, 530-546.e11.

38. Tyssowski, K. M., Letai, K. C., Rendall, S. D., Tan, C., Nizhnik, A., Kaeser, P. S., and Gray, J. M. (2019) Firing rate homeostasis can occur in the absence of neuronal activityregulated transcription, J. Neurosci., 39, 9885-9899.

39. Shepherd, J. D., and Bear, M. F. (2011) New views of Arc, a master regulator of synaptic plasticity, Nat. Neurosci., 14, 279-284.

40. Sacktor, T. C. (2011) How does PKM $\zeta$ maintain long-term memory? Nat. Rev. Neurosci., 12, 9-15.

41. McQuown, S. C., and Wood, M. A. (2011) HDAC3 and the molecular brake pad hypothesis, Neurobiol. Learn. Mem., 96, 27-34.

42. Kelly, R. D., and Cowley, S. M. (2013) The physiological roles of histone deacetylase (HDAC) 1 and 2: complex costars with multiple leading parts, Biochem. Soc. Trans., 4, 741-749.

43. Fuks, F., Burgers, W. A., Godin, N., Kasai, M., and Kouzarides, T. (2001) Dnmt3a binds deacetylases and is recruited by a sequence-specific repressor to silence transcription, EMBO J., 20, 2536-2544.

44. Fischle, W., Dequiedt, F., Hendzel, M. J., Guenther, M. G., Lazar, M. A., Voelter, W., and Verdin, E. (2002) Enzymatic activity associated with class II HDACs is dependent on a multiprotein complex containing HDAC3 and SMRT/N-CoR, Mol. Cell, 9, 45-57.

45. Galasinski, S. C., Resing, K. A., Goodrich, J. A., and Ahn, N. G. (2002) Phosphatase inhibition leads to histone deacetylases 1 and 2 phosphorylation and disruption of corepressor interactions, J. Biol. Chem., 277, 19618-19626.

46. Vaute, O., Nicolas, E., Vandel, L., and Trouche, D. (2002) Functional and physical interaction between the histone methyl transferase Suv39H1 and histone deacetylases, Nucleic Acids Res., 30, 475-481.

47. Bai, S., Ghoshal, K., Datta, J., Majumder, S., Yoon, S. O., and Jacob, S. T. (2005) DNA methyltransferase 3b regulates nerve growth factor-induced differentiation of PC12 cells by recruiting histone deacetylase 2, Mol. Cell. Biol., 25, 751-766.

48. Koshibu, K., Graff, J., Beullens, M., Heitz, F. D., Berchtold, D., Russig, H., Farinelli, M., Bollen, M., and Mansuy, I. M. (2009) Protein phosphatase 1 regulates the histone code for long-term memory, J. Neurosci., 29, 13079-13089.

49. Kundakovic, M., Chen, Y., Guidotti, A., and Grayson, D. R. (2009) The reelin and GAD67 promoters are activated by epigenetic drugs that facilitate the disruption of local repressor complexes, Mol. Pharmacol., 75, 342-354.

50. Toffolo, E., Rusconi, F., Paganini, L., Tortorici, M., Pilotto, S., Heise, C., Verpelli, C., Tedeschi, G., Maffioli, E., Sala, C., Mattevi, A., and Battaglioli, E. (2014) Phosphorylation of neuronal lysine-specific demethylase 1LSD1/KDM1A impairs transcriptional repression by regulating interaction with CoREST and histone deacetylases HDAC1/2, J. Neurochem., 128, 603-616.

51. Mathias, R. A., Guise, A. J., and Cristea, I. M. (2015) Post-translational modifications regulate class IIa histone deacetylase (HDAC) function in health and disease, Mol. Cell. Proteomics, 14, 456-470.

52. Bayraktar, G., and Kreutz, M. R. (2018) Neuronal DNA methyltransferases: epigenetic mediators between synaptic activity and gene expression? Neuroscientist, 24, 171-185.

53. Riccio, A., Alvania, R. S., Lonze, B. E., Ramanan, N., Kim, T., Huang, Y., Dawson, T. M., Snyder, S. H., and Ginty, D. D. (2006) A nitric oxide signaling pathway controls CREB-mediated gene expression in neurons, Mol. Cell, 21, 283-294.

54. Nott, A., Watson, P. M., Robinson, J. D., Crepaldi, L., and Riccio A. (2008) S-Nitrosylation of histone deacetylase 2 induces chromatin remodelling in neurons, Nature, $\mathbf{4 5 5}$, 411-415.

55. Louis Sam Titus, A. S. C., Sharma, D., Kim, M. S., and D'Mello, S. R. (2019) The Bdnf and Npas4 genes are targets of HDAC3-mediated transcriptional repression, $B M C$ Neurosci., 20, 65.

56. Guenther, M. G., Barak, O., and Lazar, M. A. (2001) The SMRT and N-CoR corepressors are activating cofactors for histone deacetylase 3, Mol. Cell. Biol., 21, 6091-6101.

57. Broide, R. S., Redwine, J. M., Aftahi, N., Young, W., Bloom, F. E., and Winrow, C. J. J. (2007) Distribution of histone deacetylases 1-11 in the rat brain, Mol. Neurosci., 31, 47-58.

58. Sando, R. 3rd, Gounko, N., Pieraut, S., Liao, L., Yates, J. 3rd, and Maximov, A. (2012) HDAC4 governs a transcriptional program essential for synaptic plasticity and memory, Cell, 151, 821-834.

59. Zhu, Y., Huang, M., Bushong, E., Phan, S., Uytiepo, M., Beutter, E., Boemer, D., Tsui, K., Ellisman, M., and Maximov, A. (2019) Class IIa HDACs regulate training and memory through dynamic experience-dependent repression of transcription, Nat. Commun., 10, 3469.

60. Chawla, S., Vanhoutte, P., Arnold, F. J., Huang, C. L., and Bading, H. (2003) Neuronal activity-dependent nucleocytoplasmic shuttling of HDAC4 and HDAC5, $J$. Neurochem., 85, 151-159.

61. Schlumm, F., Mauceri, D., Freitag, H. E., and Bading, H. (2013) Nuclear calcium signaling regulates nuclear export of a subset of class IIa histone deacetylases following synaptic activity, J. Biol. Chem., 288, 8074-8084. 
62. Josselyn, S. A., and Frankland, P. W. (2018) Memory allocation: mechanisms and function, Annu. Rev. Neurosci., 41, 389-413.

63. Zhang, C. L., McKinsey, T. A., and Olson, E. N. (2002) Association of class II histone deacetylases with heterochromatin protein 1: potential role for histone methylation in control of muscle differentiation, Mol. Cell. Biol., 22, 7302-7312.

64. Paroni, G., Cernotta, N., Dello Russo, C., Gallinari, P., Pallaoro, M., Foti, C., Talamo, F., Orsatti, L., Steinkühler, C., and Brancolini, C. (2008) PP2A regulates HDAC4 nuclear import, Mol. Biol. Cell, 19, 655-667.

65. Miller, C. A., and Sweatt, J. D. (2007) Covalent modification of DNA regulates memory formation, Neuron, 53, 857-869.

66. Du, J., Johnson, L. M., Jacobsen, S. E., and Patel, D. J. (2015) DNA methylation pathways and their crosstalk with histone methylation, Nat. Rev. Mol. Cell Biol., 16, 519532.

67. Denis, H., Ndlovu, M. N., and Fuks, F. (2011) Regulation of mammalian DNA methyltransferases: a route to new mechanisms, EMBO Rep., 12, 647-656.

68. Fuks, F., Hurd, P. J., Deplus, R., and Kouzarides, T. (2003) The DNA methyltransferases associate with HP1 and the SUV39H1 histone methyltransferase, Nucleic Acids Res., 31, 2305-2312.

69. Vasudevan, D., Bovee, R. C., and Thomas, D. D. (2016) Nitric oxide, the new architect of epigenetic landscapes, Nitric Oxide, 59, 54-62.

70. Balaban, P. M., Roshchin, M., Timoshenko, A. K., Gainutdinov, K. L., Bogodvid, T. K., Muranova, L. N., Zuzina, A. B., and Korshunova, T. A. (2014) Nitric oxide is necessary for labilization of a consolidated context memory during reconsolidation in terrestrial snails, Eur. J. Neurosci., 40, 2963-2970.

71. Gräff, J., Joseph, N. F., Horn, M. E., Samiei, A., Meng, J., Seo, J., Rei, D., Bero, A. W., Phan, T. X., Wagner, F., Holson, E., Xu, J., Sun, J., Neve, R. L., Mach, R. H., Haggarty, S. J., and Tsai, L. H. (2014) Epigenetic priming of memory updating during reconsolidation to attenuate remote fear memories, Cell, 156, 261-276, doi: 10.1016/j.cell.2013.12.020.

72. Smith, J. G., Aldous, S. G., Andreassi, C., Cuda, G., Gaspari, M., and Riccio, A. (2018) Proteomic analysis of $\mathrm{S}$-nitrosylated nuclear proteins in rat cortical neurons, Sci. Signal., 11, aar3396, doi: 10.1126/scisignal.aar3396.

73. Kornberg, M. D., Sen, N., Hara, M. R., Juluri, K. R., Nguyen, J. V., Snowman, A. M., Law, L., Hester, L. D., and Snyder, S. H. (2010) GAPDH mediates nitrosylation of nuclear proteins, Nat. Cell Biol., 12, 1094-1100.

74. Nakamura, T., and Lipton, S. A. (2013) Emerging role of protein-protein transnitrosylation in cell signaling pathways, Antioxid. Redox Signal., 18, 239-249.

75. Sen, N., and Snyder, S. H. (2011) Neurotrophin-mediated degradation of histone methyltransferase by S-nitrosylation cascade regulates neuronal differentiation, Proc. Natl. Acad. Sci. USA, 108, 20178-20183.

76. Pi, H. J., and Lisman, J. E. (2008) Coupled phosphatase and kinase switches produce the tristability required for long-term potentiation and long-term depression, $J$. Neurosci., 28, 13132-13138, doi: 10.1523/JNEUROSCI.2348-08.2008.
77. Koshibu, K., Graff, J., and Mansuy, I. M. (2011) Nuclear protein phosphatase-1: an epigenetic regulator of fear memory and amygdala long-term potentiation, Neuroscience, 173, 30-36.

78. Borodinova, A. A., Zuzina, A. B., and Balaban, P. M. (2017) Role of atypical protein kinases in maintenance of long-term memory and synaptic plasticity, Biochemistry (Moscow), 82, 243-256.

79. Chwang, W. B., O’Riordan, K. J., Levenson, J. M., and Sweatt, J. D. (2006) ERK/MAPK regulates hippocampal histone phosphorylation following contextual fear conditioning, Learn. Mem., 13, 322-328.

80. Ko, H. G., Kim, J. I., Sim, S. E., Kim, T., Yoo, J., Choi, S. L., Baek, S. H., Yu, W. J., Yoon, J. B., Sacktor, T. C., and Kaang, B. K. (2016) The role of nuclear PKM $\zeta$ in memory maintenance, Neurobiol. Learn. Mem., 135, 50-56.

81. Canettieri, G., Morantte, I., Guzmon, E., Asahara, H., Herzig, S., Anderson, S. D., Yates, J. R. 3rd, and Montminy, M. (2003) Attenuation of a phosphorylationdependent activator by an HDAC-PP1 complex, Nat. Struct. Biol., 10, 175-181.

82. Zhang, X., Ozawa, Y., Lee, H., Wen, Y. D., Tan, T. H., Wadzinski, B. E., and Seto, E. (2005) Histone deacetylase 3 (HDAC3) activity is regulated by interaction with protein serine/threonine phosphatase 4, Genes Dev., 19, 827-839.

83. Vecsey, C. G., Hawk, J. D., Lattal, K. M., Stein, J. M., Fabian, S. A., Attner, M. A., Cabrera, S. M., McDonough, C. B., Brindle, P. K., Abel, T., and Wood, M. A. (2007) Histone deacetylase inhibitors enhance memory and synaptic plasticity via CREB: CBP-dependent transcriptional activation, J. Neurosci., 27, 6128-6140.

84. Graff, J., Koshibu, K., Jouvenceau, A., Dutar, P., and Mansuy, I. M. (2010) Protein phosphatase 1-dependent transcriptional programs for long-term memory and plasticity, Learn. Mem., 17, 355-363.

85. Wooten, M. W., Zhou, G., Wooten, M. C., and Seibenhener, M. L. (1997) Transport of protein kinase C isoforms to the nucleus of PC12 cells by nerve growth factor: association of atypical zeta-PKC with the nuclear matrix, J. Neurosci. Res., 49, 393-403.

86. Sakagami, H., Kamata, A., Nishimura, H., Kasahara, J., Owada, Y., Takeuchi, Y., Watanabe, M., Fukunaga, K., and Kondo, H. (2005) Prominent expression and activitydependent nuclear translocation of $\mathrm{Ca}^{2+} /$ calmodulindependent protein kinase Idelta in hippocampal neurons, Eur. J. Neurosci., 22, 2697-2707.

87. Zhai, S., Ark, E. D., Parra-Bueno, P., and Yasuda, R. (2013) Long-distance integration of nuclear ERK signaling triggered by activation of a few dendritic spines, Science, 342, 1107-1111.

88. Melgarejo da Rosa, M., Yuanxiang, P., Brambilla, R., Kreutz, M. R., and Karpova, A. (2016) Synaptic GluN2B/CaMKII- $\alpha$ signaling induces synapto-nuclear transport of ERK and Jacob, Front. Mol. Neurosci., 9, 66.

89. Lavoie, G., Estève, P. O., Laulan, N. B., Pradhan, S., and St-Pierre, Y. (2011) PKC isoforms interact with and phosphorylate DNMT1, BMC Biol., 9, 31.

90. Wegner, M., Cao, Z., and Rosenfeld, M. G. (1992) Calcium-regulated phosphorylation within the leucine zipper of C/EBP beta, Science, 256, 370-373.

91. He, L., Sabet, A., Djedjos, S., Miller, R., Sun, X., Hussain, M. A., Radovick, S., and Wondisford, F. E. (2009) 
Metformin and insulin suppress hepatic gluconeogenesis through phosphorylation of CREB binding protein, Cell, 137, 635-646.

92. Wang, J., Weaver, I. C., Gauthier-Fisher, A., Wang, H., He, L., Yeomans, J., Wondisford, F., Kaplan, D. R., and Miller, F. D. (2010) CBP histone acetyltransferase activity regulates embryonic neural differentiation in the normal and Rubinstein-Taybi syndrome brain, Dev. Cell, 18, 114-125.

93. Gouveia, A., Hsu, K., Niibori, Y., Seegobin, M., Cancino, G. I., He, L., Wondisford, F. E., Bennett, S., Lagace, D., Frankland, P. W., and Wang, J. (2016) The aPKC-CBP pathway regulates adult hippocampal neurogenesis in an age-dependent manner, Stem Cell Rep., 7, 719-734.

94. Kwok, R. P., Lundblad, J. R., Chrivia, J. C., Richards, J. P., Bächinger, H. P., Brennan, R. G., Roberts, S. G., Green, M. R., and Goodman, R. H. (1994) Nuclear protein CBP is a coactivator for the transcription factor CREB, Nature, 370, 223-226.

95. Briand, L. A., Lee, B. G., Lelay, J., Kaestner, K. H., and Blendy, J. A. (2015) Serine 133 phosphorylation is not required for hippocampal CREB-mediated transcription and behavior, Learn. Mem., 22, 109-115.

96. Impey, S., Fong, A. L., Wang, Y., Cardinaux, J. R., Fass, D. M., Obrietan, K., Wayman, G. A., Storm, D. R., Soderling, T. R., and Goodman, R. H. (2002) Phosphorylation of CBP mediates transcriptional activation by neural activity and CaM kinase IV, Neuron, 34, 235-244.

97. Barrett, R. M., Malvaez, M., Kramar, E., Matheos, D. P., Arrizon, A., Cabrera, S. M., Lynch, G., Greene, R. W., and Wood, M. A. (2011) Hippocampal focal knockout of CBP affects specific histone modifications, long-term potentiation, and long-term memory, Neuropsychopharmacology, 36, 1545-1556, doi: 10.1038/npp.2011.61.

98. Chen, S., Cai, D., Pearce, K., Sun, P. Y., Roberts, A. C., and Glanzman, D. L. (2014) Reinstatement of long-term memory following erasure of its behavioral and synaptic expression in Aplysia, Elife, 3, e03896.
99. Rao-Ruiz, P., Couey, J. J., Marcelo, I. M., Bouwkamp, C. G., Slump, D. E., Matos, M. R., van der Loo, R. J., Martins, G. J., van den Hout, M., van IJcken, W. F., Costa, R. M., van den Oever, M. C., and Kushner, S. A. (2019) Engram-specific transcriptome profiling of contextual memory consolidation, Nat. Commun., 10, 2232.

100. Bédécarrats, A., Chen, S., Pearce, K., Cai, D., and Glanzman, D. L. (2018) RNA from trained Aplysia can induce an epigenetic engram for long-term sensitization in untrained Aplysia, eNeuro, 5, doi: 10.1523/ENEURO.0038-18.2018.

101. Maurano, M. T., Wang, H., John, S., Shafer, A., Canfield, T., Lee, K., and Stamatoyannopoulos, J. A. (2015) Role of DNA methylation in modulating transcription factor occupancy, Cell Rep., 12, 1184-1195.

102. Phillips, J. E., and Corces, V. G. (2009) CTCF: master weaver of the genome, Cell, 137, 1194-1211.

103. Sams, D. S., Nardone, S., Getselter, D., Raz, D., Tal, M., Rayi, P. R., Kaphzan, H., Hakim, O., and Elliott, E. (2016) Neuronal CTCF is necessary for basal and experience-dependent gene regulation, memory formation, and genomic structure of BDNF and Arc, Cell Rep., 17, 24182430.

104. Kim, S., Yu, N. K., Shim, K. W., Kim, J. I., Kim, H., et al. (2018) Remote memory and cortical synaptic plasticity require neuronal CCCTC-binding factor (CTCF), $J$. Neurosci., 38, 5042-5052.

105. Savell, K. E., Gallus, N. V., Simon, R. C., Brown, J. A., Revanna, J. S., Osborn, M. K., Song, E. Y., O’Malley, J. J., Stackhouse, C. T., Norvil, A., Gowher, H., Sweatt, J. D., and Day, J. J. (2016) Extra-coding RNAs regulate neuronal DNA methylation dynamics, Nat. Commun., 7, 12091, doi: 10.1038/ncomms12091.

106. Balaban, P. M., and Borodinova, A. A. (2019) Neurogenetic technologies for study mechanisms of memory maintenance, Sechenov Ross. Fiziol. Zhurn., 105, 1392-1405, doi: 10.1134/S0869813919110025. 